\title{
Exposure to bisphenol A disrupts meiotic progression during spermatogenesis in adult rats through estrogen-like activity
}

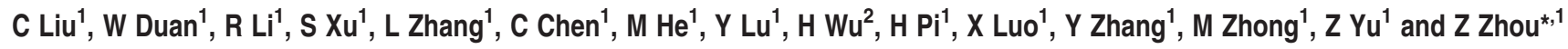

The effect of bisphenol A (BPA) on the reproductive system is highly debated but has been associated with meiotic abnormalities. However, evidence is lacking with regard to the mechanisms involved. In order to explore the underlying mechanisms of BPA-induced meiotic abnormalities in adult male rats, we exposed 9-week-old male Wistar rats to BPA by gavage at $0,2,20$ or $200 \mu \mathrm{g} / \mathrm{kg}$ body weight (bw)/day for 60 consecutive days. $17 \beta$-Estradiol $\left(E_{2}\right)$ was administered at $10 \mu \mathrm{g} / \mathrm{kg}$ bw/day as the estrogenic positive control. Treatments with $200 \mu \mathrm{g} / \mathrm{kg}$ bw/day of BPA and $E_{2}$ significantly decreased sperm counts and inhibited spermiation, characterized by an increase in stage VII and decrease in stage VIII in the seminiferous epithelium. This was concomitant with a disruption in the progression of meiosis I and the persistence of meiotic DNA strand breaks in pachytene spermatocytes,and the ataxia-telangiectasia-mutated and checkpoint kinase 2 signal pathway was also activated; Eventually, germ cell apoptosis was triggered as evaluated by terminal dUTP nick-end labeling assay and western blot for caspase 3. Using the estrogen receptor (ER) antagonist ICI 182780, we determined that ER signaling mediated BPA-induced meiotic disruption and reproductive impairment. Our results suggest that ER signaling-mediated meiotic disruption may be a major contributor to the molecular events leading to BPA-related male reproductive disorders. These rodent data support the growing association between BPA exposure and the rapid increase in the incidence of male reproductive disorders.

Cell Death and Disease (2013) 4, e676; doi:10.1038/cddis.2013.203; published online 20 June 2013

Subject Category: Experimental Medicine

Bisphenol A (BPA), a xenoestrogenic endocrine-disrupting chemical, is widely used in the manufacture of polycarbonate plastics and epoxy resins, such as food and drink containers, baby bottles, and dental sealants. In addition, almost 8 billion pounds and approximately 100 tons of BPA are released into the atmosphere every year. ${ }^{1}$ Consistent with its widespread presence, urinary BPA can be detected in $>90 \%$ of Americans. ${ }^{2}$ The possible risks of BPA to human health have caused growing concern and worldwide debates regarding its possible association with obesity, ${ }^{3}$ diabetes, ${ }^{2}$ neurobehavioral disorders, ${ }^{4}$ carcinogenic hypersensitivity, ${ }^{5}$ and reproductive impairments. ${ }^{6}$

In $>80 \%$ of sterile women, lower antral follicle counts and a smaller ovarian volume have been associated with higher levels of BPA in urine. ${ }^{7}$ Moreover, perinatal exposure to BPA results in a decline in reproductive capacity ${ }^{8}$ and alters early oogenesis in female mice. ${ }^{9}$ In males, perinatal exposure to BPA affects fertility and has the potential to induce disruptions in Sertoli cell junctional proteins, which have a crucial role in spermatogenesis. ${ }^{10}$ Furthermore, urinary BPA may be associated with decreased semen quality and increased sperm DNA damage. ${ }^{11}$ However, there is also evidence indicating that exposure to BPA does not affect the fertility of female rats ${ }^{12}$ and does not decrease the epididymal sperm count. ${ }^{13}$ Therefore, the possible reproductive impairments resulting from BPA exposure remain controversial.

Growing evidences show that BPA has the capacity to disrupt meiotic events and subsequently impair reproductive function; BPA exposure has been reported to impair chromosome synapsis and homologous chromosome segregation, ${ }^{14}$ induce synaptic defects, such as end-to-end chromosome associations and asynapsis, ${ }^{9}$ and delay meiotic progression. ${ }^{15}$ Furthermore, recent studies have demonstrated that BPA exposure inhibits meiotic double-strand break repair, ${ }^{14}$ induces meiotic aneuploidy, ${ }^{16}$ and eventually causes meiotic arrest ${ }^{17}$ or chromosomal abnormalities. ${ }^{18}$ Nevertheless, most of these studies were performed in females, and evidence is lacking with regard to the effect of BPA exposure on meiosis in males. Moreover, mechanisms with regard to BPA-induced meiotic abnormalities remain unclear.

Therefore, we performed an in vivo study to evaluate the possible effects of BPA on reproductive function and the

\footnotetext{
${ }^{1}$ Department of Occupational Health, Third Military Medical University, Chongqing, People,s Republic of China and ${ }^{2}$ Department of Occupational and Environmental Health, School of Public Health and Health Management, Chongqing Medical University, Chongqing, People's Republic of China

${ }^{*}$ Corresponding author: Z Zhou, Department of Occupational Health, Third Military Medical University, No 30, Gaotanyan Street, Shapingba District, Chongqing 400038, China. Tel: +86 23 68752289; Fax: +86 23 68752289; E-mail: lunazhou00@ 163.com

Keywords: bisphenol A; meiocyte spreading; meiosis; spermatogenesis; stage of seminiferous epithelium

Abbreviations: p-ATM, phosphorylated ataxia-telangiectasia mutated; ATR, ataxia-telangiectasia and Rad3-related; BPA, bisphenol A; p-Chk2, phosphorylated checkpoint kinase 2; CIA, chemiluminescence immunoassay; DDR, DNA damage response; mDSBs, meiotic DNA strand breaks; IgG, immunoglobulin G; $\mathrm{E}_{2}, 17 \beta$-estradiol; ER, estrogen receptor; $\mathrm{FSH}$, follicle-stimulating hormone; H\&E, hematoxylin and eosin; $\mathrm{LH}$, luteinizing hormone; PI, propidium iodide; PAS-H, periodic acid schiff-hematoxylin; RIA, radioimmunoassay; TUNEL, terminal dUTP nick-end labeling

Received 06.2.13; revised 07.5.13; accepted 08.5.13; Edited by A Stephanou
} 
progress of meiosis in adult male rats and to explore relevant mechanisms involved.

\section{Results}

ER antagonism abolished the BPA-induced sperm count reduction. After 60 consecutive days of exposure, treatment with $200 \mu \mathrm{g} / \mathrm{kg} / \mathrm{d}$ of BPA and $17 \beta$-estradiol $\left(E_{2}\right)$ significantly reduced the epididymal sperm counts; the effect of BPA was reversed by $\mathrm{ICl}$ pretreatment (Figure 1a). A histological examination showed fewer sperm in the cauda epididymal ducts following BPA treatment at $200 \mu \mathrm{g} / \mathrm{kg} / \mathrm{d}$ compared with the control group, which was abolished by $\mathrm{ICI}$ pretreatment (Figures 1e-l). Nevertheless, no significant difference was found in relative body weight, testes weight, or epididymides weight (Figures $1 \mathrm{~b}-\mathrm{d}$ ). However, $\mathrm{E}_{2}$ administration significantly reduced the relative epididymides weight (Figure 1d).

\section{No changes in sperm parameters or serum sex hormone} levels. We evaluated sperm parameters and sex hormone levels to explore the underlying mechanism of the decreased sperm counts. No significant differences were found in sperm motility (Figure 2a) or morphology (Figure 2b). Annexin V/propidium iodide (PI) staining also demonstrated no changes in apoptotic sperm (Figure 2c). Moreover, following BPA treatment, no significant differences were observed in serum follicle-stimulating hormone (FSH), luteinizing hormone ( $\mathrm{LH})$, or testosterone levels, which regulate spermatogenesis (Figures 2d-f). However, we found a greater than threefold reduction in the serum testosterone level following $E_{2}$ treatment (Figure 2f).

ER antagonism blocked BPA-inhibited spermiation. The lack of alteration in sperm parameters and sex hormone levels suggested that BPA may directly exert its effect on the testes. An analysis of the seminiferous epithelium stage revealed that the alterations were focused in stages VII, VIII, and IX. Significant increases in stages VII and IX and decrease in stage VIII were observed following BPA administration; rats treated with $\mathrm{E}_{2}$ displayed similar results (Figure 3a). In the next experiment, we found that $\mathrm{ICl}$ pretreatment significantly reversed the BPA-induced increase in stage VII (Figure $3 \mathrm{~b}$ ) and BPA-induced decrease in stage VIII (Figure 3c).

ER antagonism prevented BPA-induced meiotic disruption. As previously described, ${ }^{19}$ FACS analysis of all testicular cells showed three peaks according to cellular DNA content: $1 \mathrm{C}, 2 \mathrm{C}$, and $4 \mathrm{C}$ cells. $1 \mathrm{C}$ cells were typically spermatids, $2 \mathrm{C}$ cells included somatic cells, spermatogonia, and secondary spermatocytes, and $4 \mathrm{C}$ cells represented cells in the G2/M phase and primary spermatocytes. BPA 200- (Figure 4Ab) and $E_{2^{-}}$(Figure 4Ac) treated rats showed an increase in $4 \mathrm{C}$ cells and a decrease in $1 \mathrm{C}$ cells after treatment compared with the control group (Figure 4Aa).
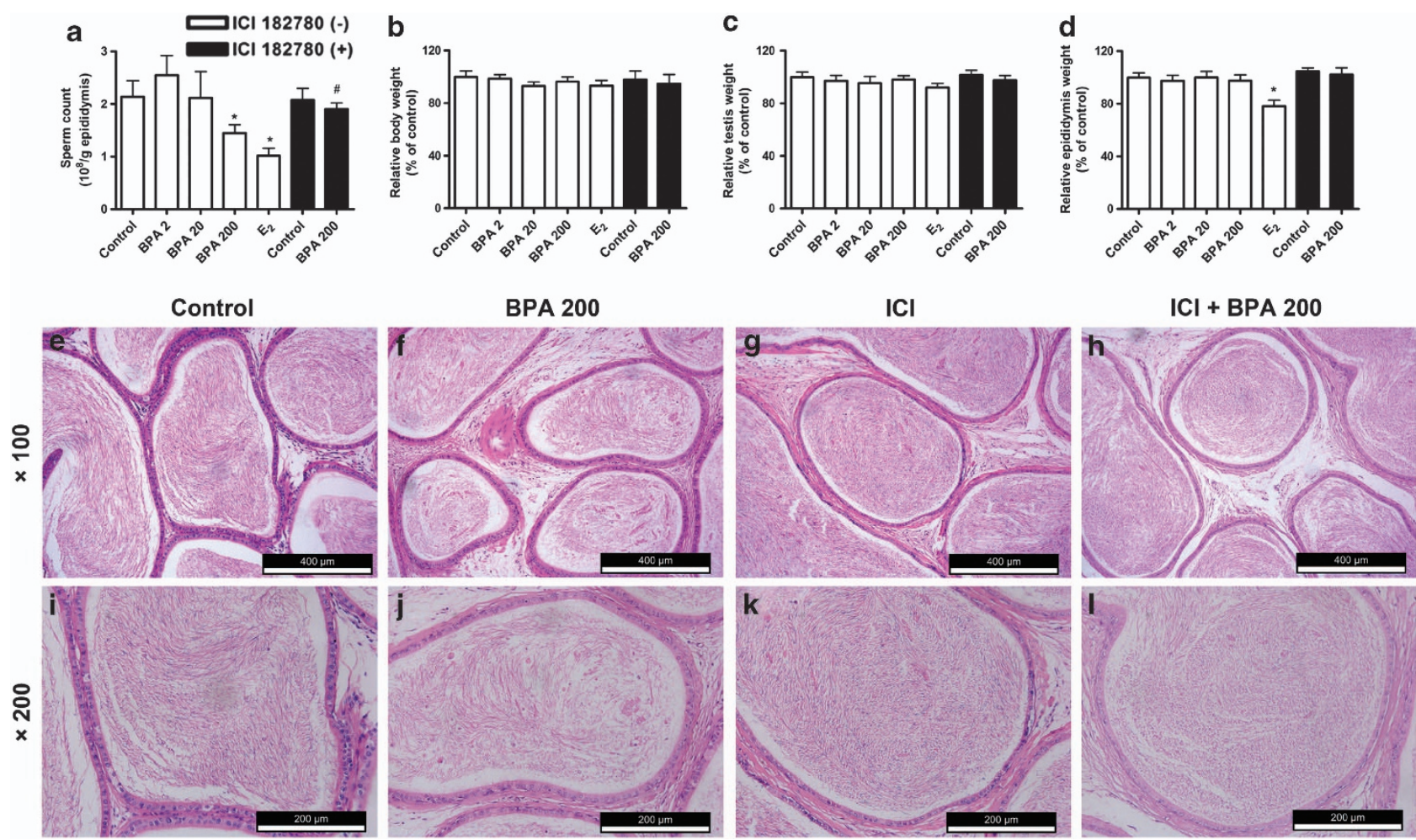

Figure 1 Effects of BPA and $\mathrm{E}_{2}$ on (a) cauda epididymal sperm counts, (b) relative body weight, (c) testis weight, (d) epididymis weight, and (e-l) the cauda epididymis histology with or without ICl 182780 pretreatment. Rats were treated with BPA $(0,2,20,200 \mu \mathrm{g} / \mathrm{kg} / \mathrm{d}), \mathrm{E}_{2}(10 \mu \mathrm{g} / \mathrm{kg} / \mathrm{d})$, or BPA 200 and ICl (500 $\left.\mu \mathrm{g} / \mathrm{kg} / \mathrm{d}\right)$ for 60 days. Bars represent the mean \pm S.E.M. ( $n=$ eight rats per group), ${ }^{\star} P<0.05$ versus control, ${ }^{\#} P<0.05$ versus BPA 200 
a

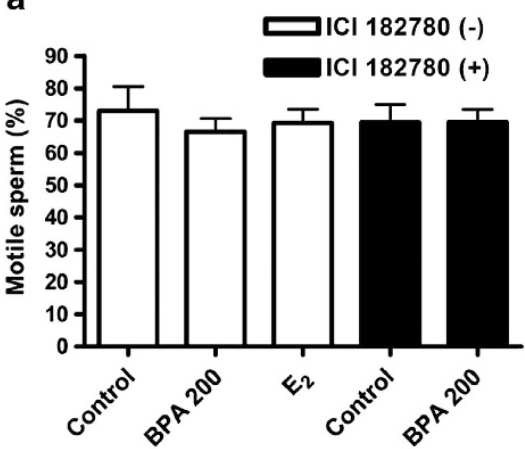

d

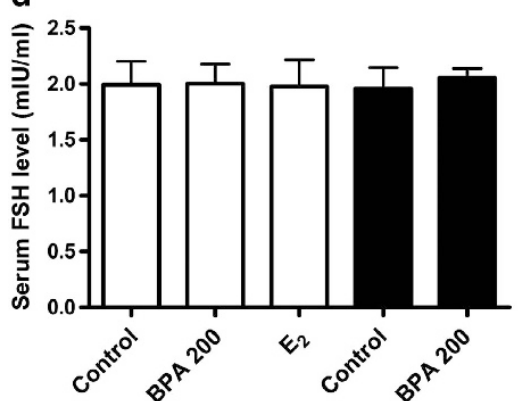

b

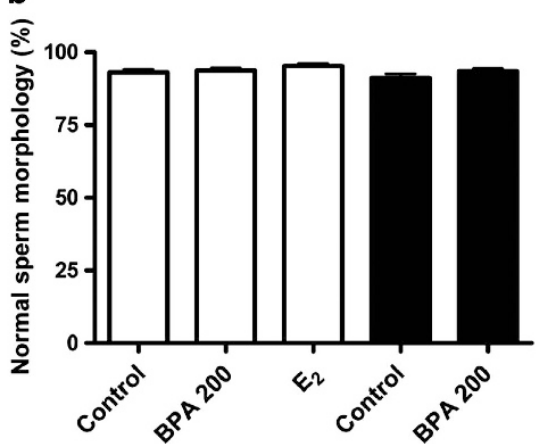

e

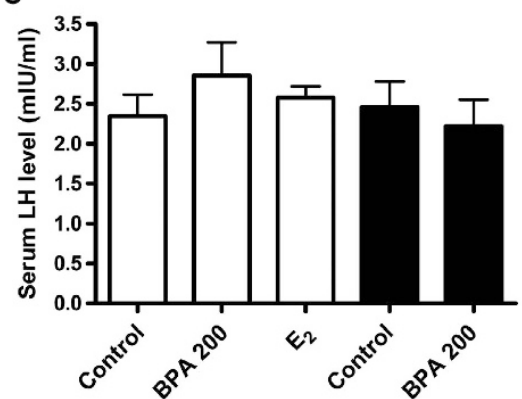

C

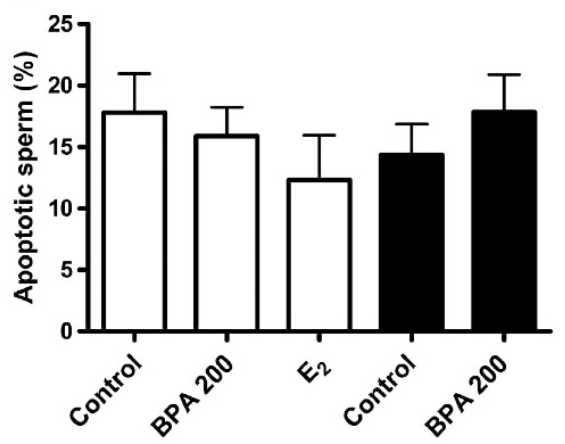

$\mathbf{f}$

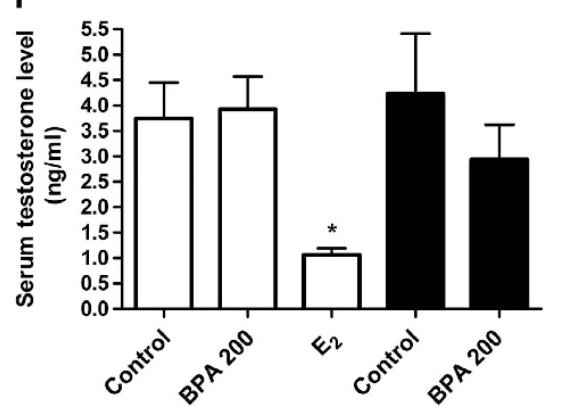

Figure 2 Effect of BPA or $\mathrm{E}_{2}$ administration on sperm parameters and serum sex hormone levels with or without ICl 182780 pretreatment. No alterations were observed in (a) sperm motility, (b) percentage of normal sperm morphology, (c) apoptotic sperm, (d) serum FSH levels, or (e) serum LH levels. (f) Serum testosterone levels were significantly reduced following $\mathrm{E}_{2}$ but not BPA and ICI treatment. Each bar represents the mean \pm S.E.M. ( $n=$ eight rats per group). ${ }^{*} P<0.05$ versus control
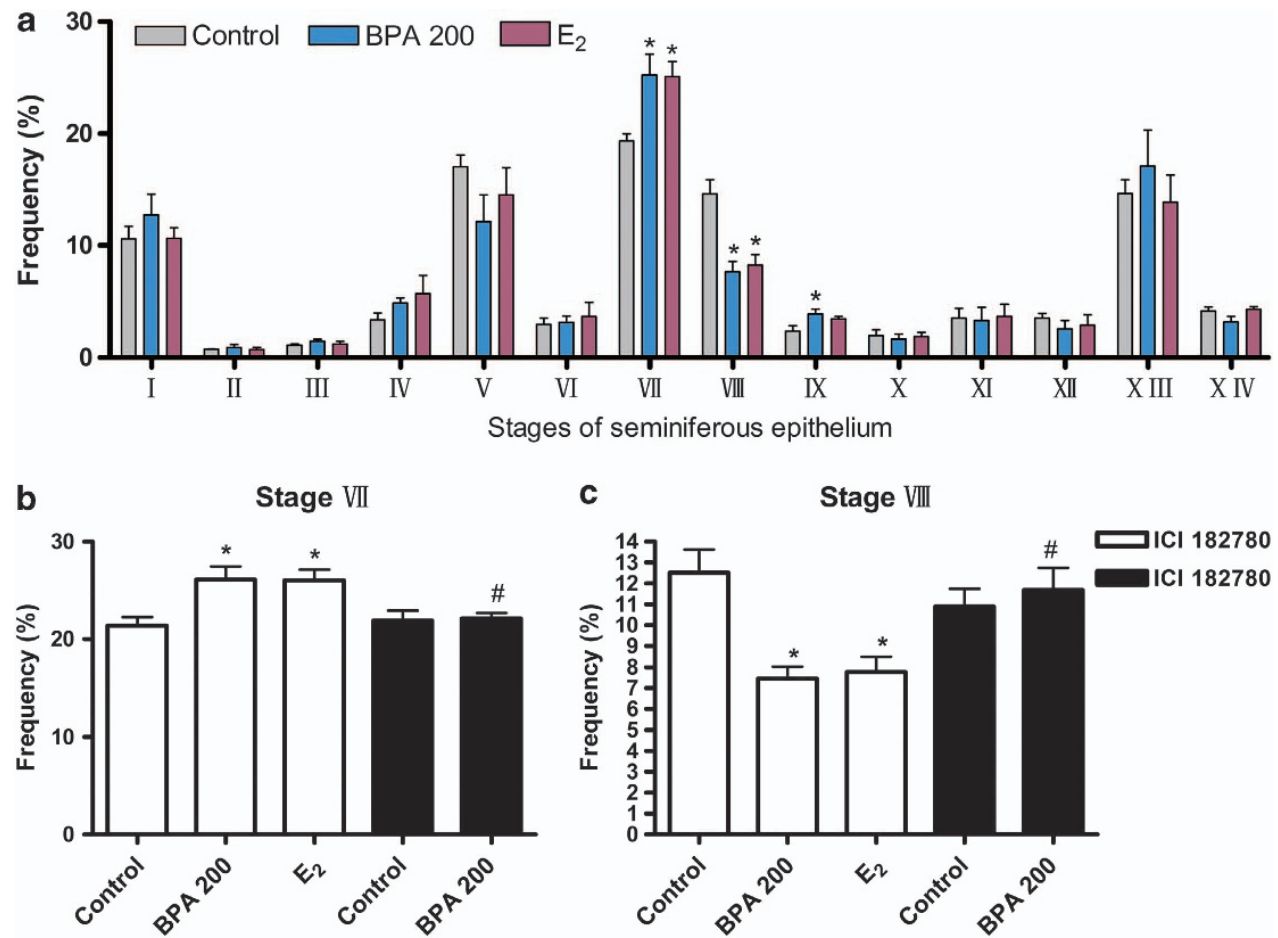

C

Stage VIII

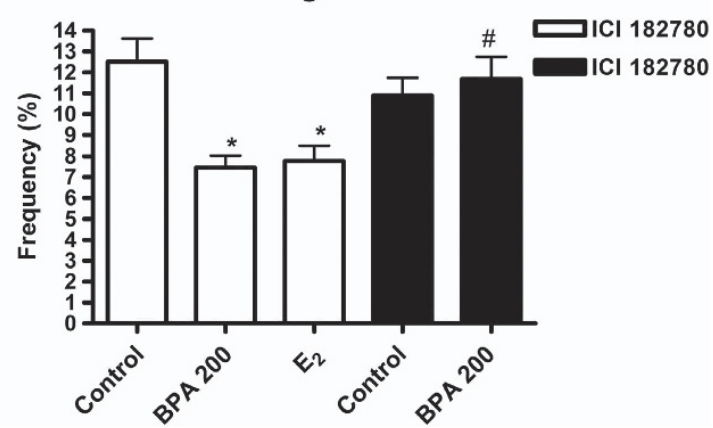

Figure 3 Effects of BPA and $E_{2}$ on the seminiferous epithelium stages with or without ICI 182780 pretreatment. (a) The percentages of the 14 stages are presented. (b) The percentage of stage VII. (c) The percentage of stage VIII. Each bar represents the mean \pm S.E.M. ( $n=$ eight rats per group), ${ }^{*} P<0.05$ versus control, ${ }^{\sharp} P<0.05$ versus BPA 200 
A a

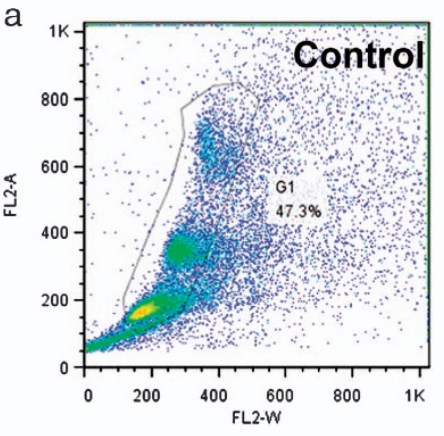

B a

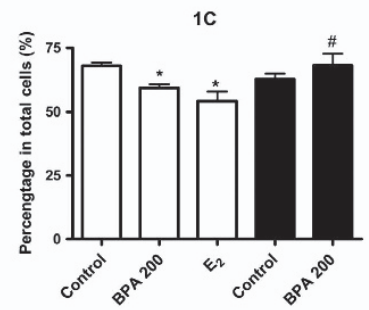

b

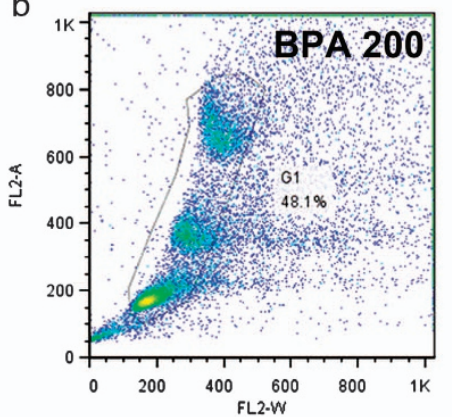

b

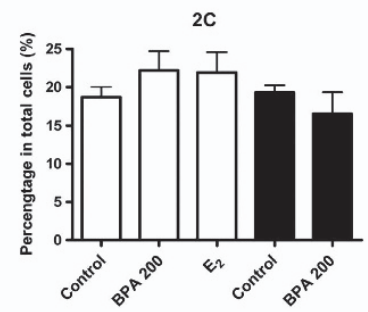

C

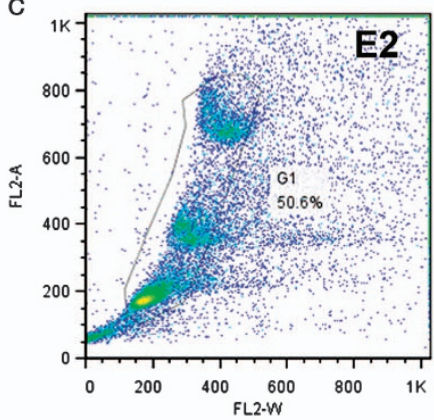

C
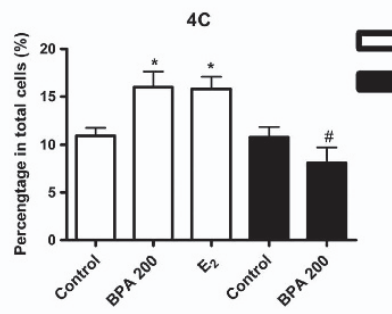
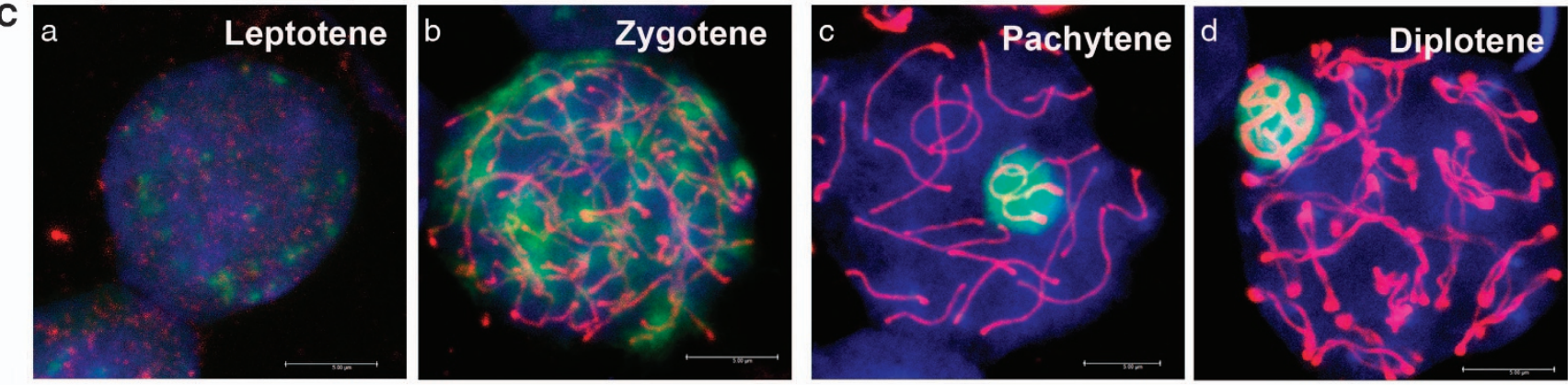

D a

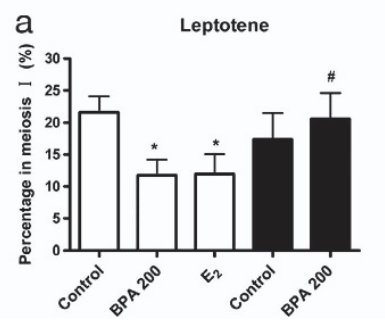

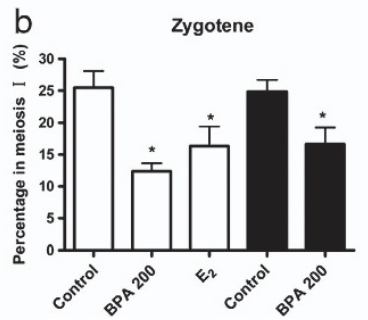

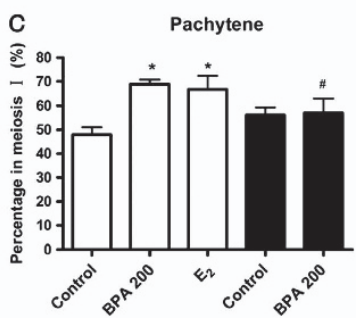

ICI 182780 (-)

ICI 182780 (+)
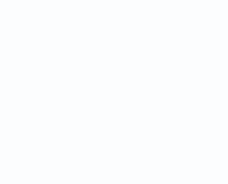

Figure 4 Changes in the proportions of testicular cell populations and stages of spermatocytes in meiosis I following BPA and $\mathrm{E}_{2}$ treatment with or without ICl 182780 pretreatment. (Aa-Ac) Representative fluorescence-activated cell sorting images of all testicular cells from control (Aa), BPA $200-(\mathbf{A b})$ and $E_{2^{-}}(\mathbf{A c})$ treated rats. (Ba-Bd) The proportion of $1 \mathrm{C}, 2 \mathrm{C}$, and $4 \mathrm{C}$ testicular germ cells ( $n=$ six rats per group). (Ca-Cd) Spermatocytes in the meiosis I stages. Meiotic chromosomal spreads were prepared from freshly dissected testes from normal rats; spermatocytic reparations were stained with SYCP3 (red), mouse $\gamma$ H2AX (green), and DAPI (4,6-diamidino-2-phenylindole; blue). Representative images of leptotene $(\mathbf{C a})$, zygotene $(\mathbf{C b})$, pachytene $(\mathbf{C} \mathrm{c})$, and diplotene $(\mathbf{C d})$ spermatocytes are shown. (Da-Dd) The percentages of spermatocytes in the meiosis I stages, above 100 pachytene spermatocytes of each rat ( $n=$ six rats per group) were analyzed. ${ }^{*} P<0.05$ versus control, ${ }^{\#} P<0.05$ versus BPA 200

BPA administration significantly reduced the percentage of $1 \mathrm{C}$ cells (Figure $4 \mathrm{Ba}$ ) and increased the percentage of $4 \mathrm{C}$ cells (Figure $4 \mathrm{Bc}$ ), which were prevented by $\mathrm{ICI}$ pretreatment (Figures 4Ba and $\mathrm{Bc}$ ). However, no significant differences were found in $2 \mathrm{C}$ cells between the groups (Figure $4 \mathrm{Bb}$ ).

To further explore how BPA disrupts meiotic progression, we utilized SYCP3, $\gamma \mathrm{H} 2 \mathrm{AX}$, and DAPI staining to investigate the specific spermatocyte stages in meiosis I: leptotene (Figure 4Ca), zygotene (Figure 4Cb), pachytene (Figure 4Cc), and diplotene (Figure 4Cd) spermatocytes, as previously described. ${ }^{20}$ Both BPA and $\mathrm{E}_{2}$ administration significantly reduced the percentage of spermatocytes in the leptotene
(Figure 4Da) and zygotene stages (Figure 4Db) and increased the percentage of spermatocytes in the pachytene stage (Figure 4Dc) compared with the control group, which were significantly inhibited by $\mathrm{ICl}$ pretreatment (Figures 4Da and Dc). However, no significant differences were found in the diplotene stage between the groups (Figure 4Dd).

ER antagonism blocked BPA-induced persistent meiotic DNA strand breaks (mDSBs) and checkpoint activation in pachytene spermatocytes. In spermatocytes, $\gamma \mathrm{H} 2 \mathrm{AX}$ is spatially and temporally linked to mDSBs in the leptotene and zygotene stages, and in the pachytene stage, 
disappears from synapsed autosomes but remains on the sex chromosomes. ${ }^{21}$ However, unresolved mDSBs or their accumulations in the pachytene stage may delay meiotic progression. $^{22}$ Thus, experiments were conducted to determine whether BPA could induce the persistence of mDSBs. As shown in Figure $5 \mathrm{a}$, normal rat spermatocytes in the pachytene stage demonstrated intense immunopositive staining for $\gamma \mathrm{H} 2 \mathrm{AX}$ localized to the sex body, which contains the unpaired regions of the $\mathrm{X}$ and $\mathrm{Y}$ chromosomes; $\gamma \mathrm{H} 2 \mathrm{AX}$ immunostaining of the autosomes showed few or negative foci on each pachytene spermatocyte. However, pachytene spermatocytes obtained from BPA- and $E_{2}$-treated rats showed a clear increase in $\gamma \mathrm{H} 2 \mathrm{AX}$ foci on the autosomes. In addition, these pachytene spermatocytes exhibited chromosomal abnormalities, including asynapsis, chromosomal aberrations, and interrupted regions of SYCP3 staining. The percentage of $\gamma \mathrm{H} 2 \mathrm{AX}$-positive spermatocytes significantly increased following both BPA and $\mathrm{E}_{2}$ administration. However, this BPA-induced increase was blunted following $\mathrm{ICl}$ pretreatment, although there was still a significant difference compared with the control group (Figure 5c). These effects of BPA and $E_{2}$ were confirmed by an alkaline comet assay to detect the extra mDSBs in pachytene spermatocytes. Following BPA and $\mathrm{E}_{2}$ treatment, a significant increase was found in tail moment compared with the control group. This BPA-induced increase was also blocked following $\mathrm{ICl}$ pretreatment (Figure $5 \mathrm{~d}$ ). Furthermore, results from western blot showed an increased levels of $\gamma \mathrm{H} 2 \mathrm{AX}$ in BPA- and E2-treated rats, which was also abolished following $\mathrm{ICl}$ pretreatment (Figure 5e). In pachytene spermatocytes, the phosphorylated ataxia-telangiectasia mutated ( $p-A T M)$ signals clearly overlapped with the XY chromosomes, which were still unsynapsed at this stage. Following BPA and E2 exposure, the p-ATM signals became diffuse around the $X Y$ chromosomes and also on the autosomes (Figure $5 b$ ). Western blot showed that BPA and $E_{2}$ treatments significantly increased the levels of its downstream signal phosphorylated checkpoint kinase 2 (p-Chk2), but these increases in BPA-treated rats were blocked by $\mathrm{ICl}$ pretreatment (Figure 5f).

ER antagonism abolished BPA-induced germ cell apoptosis. Considering that ATM/Chk2-mediated checkpoint activation may result in not only cell-cycle delay but also apoptosis if the mDSBs were not properly repaired, we investigated whether germ cell apoptosis was triggered. Following BPA and $E_{2}$ treatments, there was a significant elevation of testicular apoptotic cells, as examined by terminal dUTP nick-end labeling (TUNEL) staining (Figure 6a). Apoptotic cells occur predominantly in spermatogonia and primary spermatocytes and less in secondary spermatocytes. Semi-quantitative analysis by TUNEL-positive cells/100 seminiferous tubules showed that there was a significantly higher incidence of testicular apoptotic cell in BPA-treated rats than control rats, which could be almost completely attenuated by $\mathrm{ICI}$ pretreatment (Figure 6b).

The apoptosis was initiated by a caspase cascade. We therefore addressed whether BPA-induced apoptosis was through caspase signaling. Caspase-3 converged with various death signals and has a key role in inducing apoptosis; thus, the expression of active caspase- 3 were determined in this study. As expected, BPA and $E_{2}$ treatments increased the expression of active caspase-3. Following ICI pretreatment, the active caspase- 3 activities were blocked (Figures $6 c$ and d).

\section{Discussion}

The results demonstrated BPA-induced meiotic abnormalities in the male reproductive system in adult rats. In vivo, BPA administration at $200 \mu \mathrm{g} / \mathrm{kg}$ bw/d significantly decreased sperm counts in adult male rats as a result of spermiation inhibition, with no changes in relative body or reproductive organ weight, no alterations in sperm parameters and sperm apoptosis, and no impacts on sex hormone levels. The sperm count reduction was associated with a disruption in meiotic progression and apoptosis in testicular cells, which may have been caused by the persistence of mDSBs in the pachytene stage in male BPA-exposed rats and the ATM/Chk2 signals activation. Using $E_{2}$ and the ER antagonist ICI 182780, we determined that ER signaling mediated BPA-induced reproductive impairments.

The doses of BPA administered in this study are selected with human applicability in mind. Recent studies suggest that an adult is exposed to low concentrations of BPA, no more than $0.4-1.5 \mu \mathrm{g} \mathrm{BPA} / \mathrm{kg}$ bw/day. ${ }^{23}$ The environmentally human-relevant dose of BPA in rodent experiments is considered as $20 \mu \mathrm{g} / \mathrm{kg} \mathrm{bw} / \mathrm{day}^{9}{ }^{9}$ Although the dose of BPA (200 $\mu \mathrm{g} / \mathrm{kg}$ bw/day) that induced significant reproductive impairment in our study cannot be considered truly environmentally relevant, it can be considered low. Based on the available data, a conference sponsored by the National Institute of Environmental Health Sciences in 2007 predicted that internal BPA exposure (plasma or serum concentrations) in humans is $>35 \mathrm{mg} /$ day $(\sim 500 \mu \mathrm{g} / \mathrm{kg} /$ day $) .{ }^{24}$ Moreover, the actual exposure level may be much higher than the current accepted level in some countries or areas. ${ }^{25}$

Epidemiological evidence suggests that increased urine BPA levels are highly associated with decreased sperm concentrations, ${ }^{6}$ indicating an underlying link between BPA exposure and sperm production. In the present study, following a 60-day exposure of adult rats to BPA and $E_{2}$, a significant reduction of sperm counts was observed at dosages up to $200 \mu \mathrm{g} / \mathrm{kg} / \mathrm{d}$, which is consistent with previous studies showing that adult BPA exposure adversely affects epididymal sperm counts. ${ }^{26-28}$ However, some studies that conducted perinatal, neonatal, gestational, or even adult BPA exposure failed to observe any changes in sperm counts, ${ }^{29}$ which may be attributed to their different exposure protocols and shorter duration compared with our study.

In rodent testes, the multiple types of germ cells are arranged in characteristic cellular associations that succeed each other in a given area of the seminiferous tubule, which are known as the stages of spermatogenesis. Their succession in time has been defined as the cycle of the seminiferous epithelium. Interestingly, in our study, the BPA- and $E_{2}$-treated groups showed a higher frequency of stage VII and a lower frequency of stage VIII compared with control animals, suggesting a possible delay in the progression of spermiation, which takes place at stage VIII. These results are consistent with previous studies showing that environmental toxin-induced low daily sperm production and low epididymal 
a
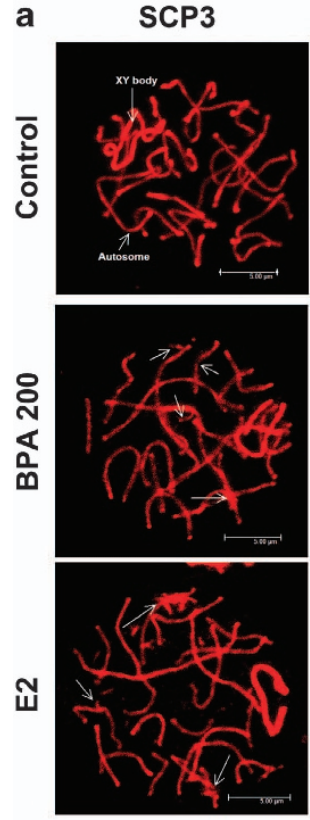

yH2AX
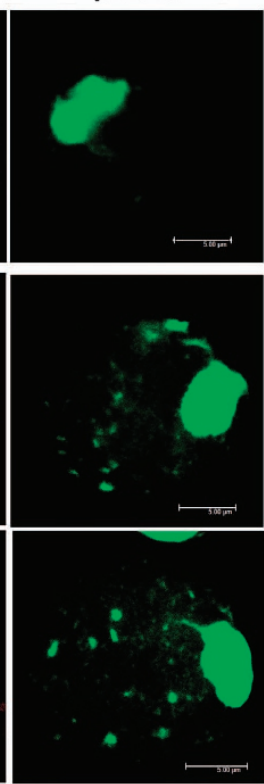

Overlay
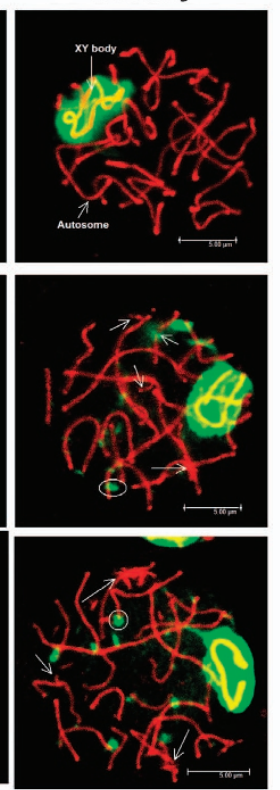

b
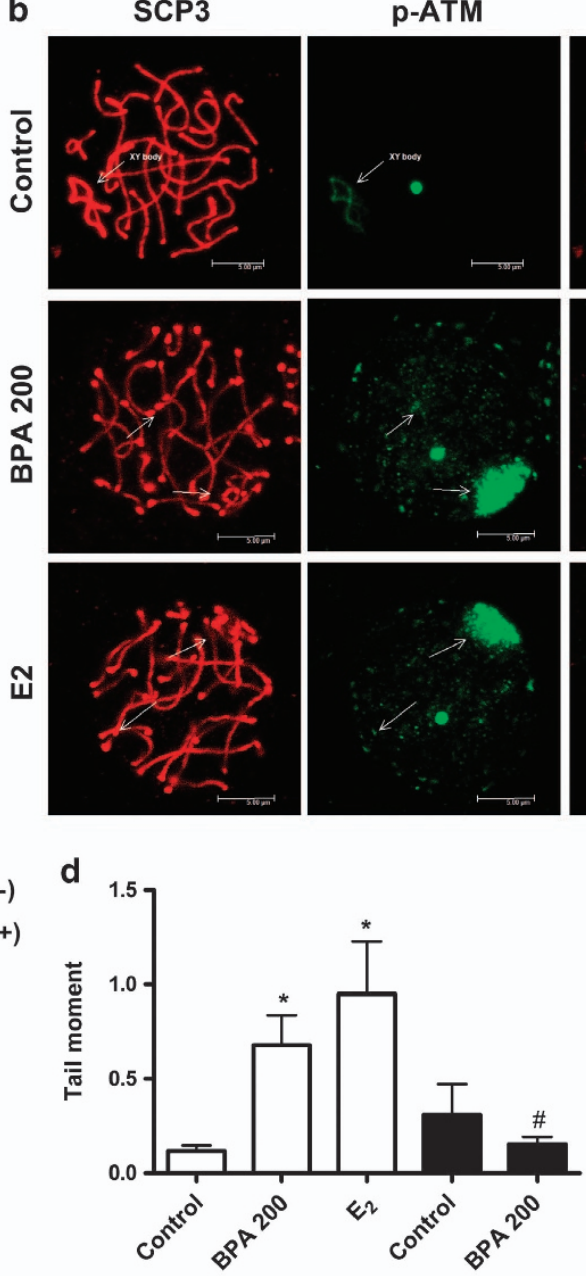

f p-Chk2

$\beta$-actin

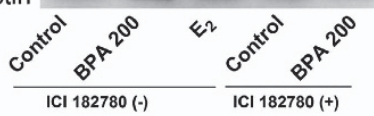

p-Chk2 (T383) vs actin

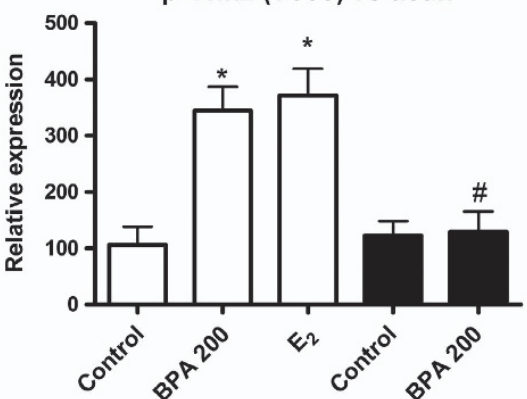

Figure 5 Persistence of mDSBs and checkpoint activation assessed by chromosomal spread, comet assay and immunoblot after BPA, $\mathrm{E}_{2}$, and/or combined ICI treatment. (a) Photomicrographs from the control, BPA 200, and $\mathrm{E}_{2}$ groups show abnormal $\gamma \mathrm{H} 2 \mathrm{AX}$ foci formation (white circle) and chromosome abnormalities (white arrow) on the autosomes of pachytene spermatocytes; (b) photomicrographs show ATM activation on both autosome and XY body in pachytene spermatocytes; (c) quantification of $\gamma$ H2AXpositive cells in pachytene spermatocytes, above 100 pachytene spermatocytes of each rat ( $n=$ six rats per group) were analyzed; (d) levels of mDSBs determined by alkaline comet assay; (e) immunoblotting analysis of whole-testis lysates showing an accumulation of $\gamma \mathrm{H} 2 \mathrm{AX}$ in BPA- or $\mathrm{E}_{2}$-treated testis, which can be blocked by ICl pretreatment; (f) the levels of phosphospecific forms of Chk2 were assessed using western blot analysis, in which actin served as a loading control, vehicle-treated rats were arbitrarily fixed at $100 \%$. Bars represent the mean \pm S.E.M. ( $n=$ six rats per group), ${ }^{*} P<0.05$ versus control, ${ }^{\#} P<0.05$ versus BPA 200 
a
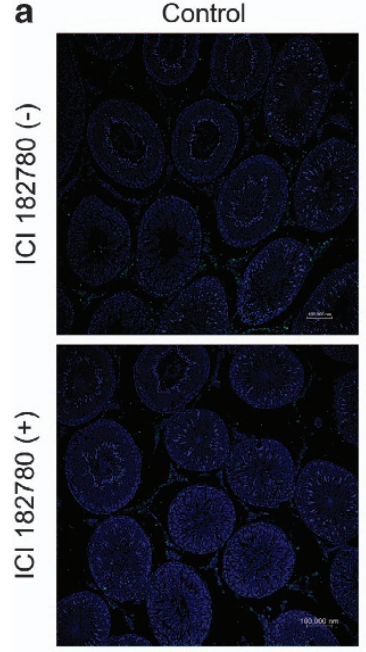

C

Total caspase 3

Active caspase 3
BPA 200
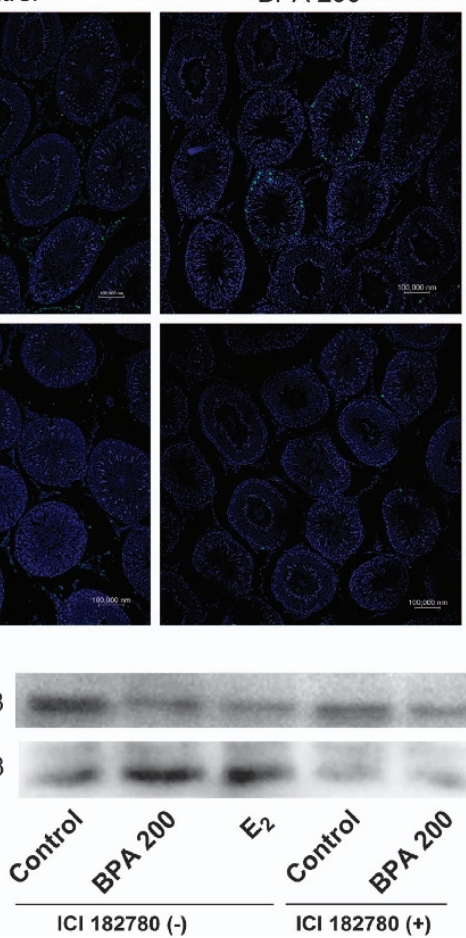

b

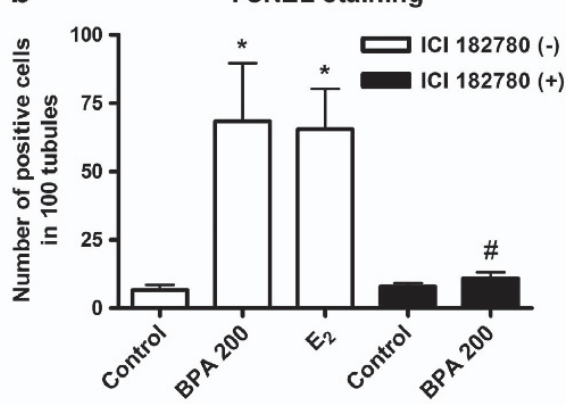

d

Active caspase 3

vs

total caspase 3

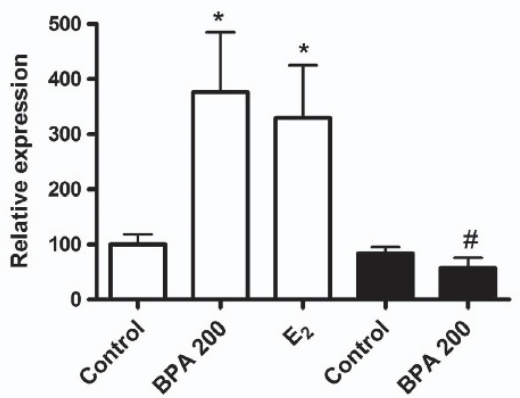

Figure 6 Germ cell apoptosis evaluated by TUNEL assay and caspase-3 immunoblot after BPA and $\mathrm{E}_{2}$ treatment with or without ICl pretreatment. (a) Representative micrographs show TUNEL-positive cells (green) on testicular section from control, BPA, and/or ICl-treated rats. Nuclei were counterstained with DAPI (4,6-diamidino-2-phenylindole; blue). (b) Quantification of TUNEL analyses. Shown is the number of positive cells per 100 seminiferous tubules of each rat $(n=\operatorname{six}$ rats per group). (c) Immunoblot of active caspase-3 performed on testicular protein extracts. Shown is the representative micrographs. (d) Quantification of activated caspase-3 protein accumulation relative to total caspase-3 is shown; vehicle-treated rats were arbitrarily fixed at $100 \%$ ( $n=$ six rats per group). ${ }^{*} P<0.05$ versus control, ${ }^{\#} P<0.05$ versus BPA 200

sperm counts are concomitant with an increased frequency of stage $\mathrm{VII}^{30}$ and a reduction in the length of stage VIII. ${ }^{31}$ Furthermore, BPA and estrogen have also been shown to induce blood-testis barrier restructuring, ${ }^{32}$ Sertoli cell junctional protein expression, ${ }^{10}$ and germ cell apoptosis, specifically at stages VII and VIII. ${ }^{33}$ Although we did not evaluate these changes, our data indicate that the BPA-induced sperm count reduction is highly associated with the disruption of spermatogenesis. However, because the sex hormones important for controlling the process of spermatogenesis were not altered after BPA treatment, we attempted to unequivocally demonstrate how spermatogenesis is disturbed by BPA exposure.

Results from flow cytometric and immunofluorescent analysis of meiotic cells reflected the retention of primary spermatocyes at post-meiotic stage that failed to be differentiated into spermatids following BPA exposure and $E_{2}$ treatment. Meiotic progression is regulated by many factors, including those involved in $\mathrm{mDSB}$ repair and homologous recombination, and structural proteins. Mutation of some of the genes involved in $\mathrm{mDSB}$ repair results in the arrest of spermatocytes at the pachytene stage,${ }^{34,35}$ suggesting that the pachytene stage may act as a checkpoint to monitor mDSB repair and meiotic events during germ cell development. In the present study, coupled with the retention of pachytene spermatocytes, a marked increase of $\gamma \mathrm{H} 2 \mathrm{AX}$ foci formation on the autosomes of pachytene spermatocytes is observed following BPA and $E_{2}$ treatments, indicating that BPA and $E_{2}$ induced the accumulation of $\mathrm{mDSBs}$ in pachytene spermatocytes. Additionally, previous studies have also demonstrated that BPA exposure impairs the double-strand break repair machinery, increases the number of homologous recombination protein RAD-51 foci in late pachytene, ${ }^{14}$ elevates mismatch repair-related $\mathrm{MLH} 1$ foci, ${ }^{9,15}$ and upregulates the expression of genes involved in DSB generation (Spo11), signaling (H2AX), and repair (RPA, BML). ${ }^{36}$ These results suggest that exposure to a low dose of BPA may lead to the persistence of mDSBs by inhibiting their repair, although high doses of BPA have been reported to be genotoxic. ${ }^{37}$ Subsequently, these unresolved mDSBs in pachytene spermatocytes result in the disruption of meiotic progression and chromosome abnormalities, such as asynapsis, chromosomal aberrations, and interrupted regions of SYCP3 staining, as also demonstrated by previous studies. ${ }^{9,14}$

In response to DSBs, mammalian cells activate checkpoint kinases and a complex response network, including DNA damage sensors, signal transducers, and effectors which is named as DNA damage response (DDR). ${ }^{38,39}$ Two of the major regulators of the DDR are ATM and ataxia-telangiectasia and Rad3-related (ATR). ${ }^{40}$ ATM and ATR signals control cell-cycle transitions, DNA replication, DNA repair, and apoptosis. ATM mainly responds to DSBs, whereas ATR reacts to the structures that contain single-stranded DNA. ${ }^{41}$ In the present study, concomitant with the persistence of $\gamma \mathrm{H} 2 \mathrm{AX}$, the $\mathrm{p}$-ATM and $\mathrm{p}$-Chk2 are greatly upregulated following BPA 200 and $E_{2}$ treatments, which indicate that the ATM/Chk2 signals are involved in 
BPA- and $E_{2}$-induced meiotic cycle delay and germ cell apoptosis. In meiosis, the ATM/Chk2 signals regulate meiotic entry and meiotic $\mathrm{G}(2) / \mathrm{M}$ transition in germ cells. ${ }^{42}$ Our results suggest that ATM/Chk2-dependent meiotic cycle delay and germ cell apoptosis may contribute to the BPA- and $\mathrm{E}_{2}$-induced sperm count reduction.

BPA is considered a weak estrogen because its binding affinity to $\mathrm{ER} \alpha$ and $\mathrm{ER} \beta$ was estimated to be $>1000-10000$ fold lower than the natural hormone $E_{2} \cdot{ }^{43}$ However, previous studies have revealed that BPA can promote estrogen-like activities that are similar or stronger than $E_{2} \cdot{ }^{44}$ We find that BPA acts as an ER agonist to induce persistent mDSBs in pachytene spermatocytes, triggering subsequent meiotic disruption. However, our results are inconsistent with previous studies showing that BPA acts as an ER antagonist to induce meiotic abnormalities. ${ }^{9}$ These conflicting outcomes indicate that BPA activity is effect and sex dependent and may be attributed to the differential expression and balance of ERs. In the adult testes and in stages VII-XIV, ER $\alpha$ is expressed at higher levels. Its transcripts have been shown to vary according to age, germ cell type, and the stage of the seminiferous epithelium, whereas ER $\beta$ expression is less affected by these. ${ }^{45}$ Therefore, our data suggest that the BPAinduced persistence of $\mathrm{mDSBs}$ and the subsequent disruption of meiotic disruption are ER dependent. However, it is unclear how ER signaling induces mDSB persistence. It has been demonstrated that estrogen may block ATR activity via plasma membrane-localized $\mathrm{ER} \alpha$ to inhibit cell-cycle checkpoints and DNA repair. ${ }^{46}$ As a result of the persistence of $\mathrm{mDSBs}$ and disrupted meiotic progression, the BPA-induced sperm count reduction is also ER dependent, as indicated by a previous study demonstrating that $\mathrm{ICl}$ treatment partially reverses the diethylstilbestrol-induced decline in sperm concentration. Nevertheless, ICI treatment has previously been described to have deleterious effects on male reproductive outcomes. ${ }^{47}$ In our study, due perhaps to the lower dose or shorter duration of $\mathrm{ICI}$, we failed to observe any alterations following $\mathrm{ICI}$ treatment alone.

In summary, our present results suggest that ER-mediated and ATM/Chk2-dependent meiotic disruption may be a major contributor to the molecular events leading to BPA-related male reproductive disorders.

\footnotetext{
Materials and Methods

Animal care and diets. Male Wistar rats (8 weeks of age) were purchased from the Animal Center of the Third Military Medical University, Chongqing, China. Animal care and use were conducted according to our national and institutional guidelines. All animals were housed under standard conditions $\left(23 \pm 1^{\circ} \mathrm{C}\right.$, $55 \pm 5 \%$ humidity, $12-h$ light/dark cycle). Animals were provided with a rodent experimental diet from Research Diets (Harlan Teklad, Madison, WI, USA) in which no phytoestrogens could be detected, as introduced by the manufacturer. Water was given from glass bottles ad libitum. All animals in this study were treated humanely and with regard for the alleviation of suffering.

Experimental design. Rats acclimatized for 1 week were administered BPA (Sigma-Aldrich, St. Louis, MO, USA) by gavage at 0 (ethanol only), 2, 20, and $200 \mu \mathrm{g} / \mathrm{kg}$ bw/day, according to previous studies. ${ }^{5,9} E_{2}$ (Sigma-Aldrich) was administered by subcutaneous injection at $10 \mu \mathrm{g} / \mathrm{kg}$ bw/day as an estrogenicpositive control. ${ }^{48} \mathrm{BPA}$ and $\mathrm{E}_{2}$ were dissolved in absolute ethanol and then mixed with corn oil (Sigma-Aldrich) to final absolute ethanol concentration of $0.5 \%$. After treatment, changes in body weight, testis weight, epididymal weight, and epididymal sperm counts were evaluated. For the following experiment, fulvestrant
}

(ICI 182780; Sigma-Aldrich) was used to antagonize ER signaling and was dissolved in absolute ethanol with a final dose of $500 \mu \mathrm{g} / \mathrm{kg}$ bw/day. ${ }^{49}$ Acclimatized rats were randomly divided into five groups: control, BPA 200, $\mathrm{E}_{2}, \mathrm{ICl}$, and $\mathrm{ICl}+\mathrm{BPA} 200$. Rats in the $\mathrm{ICl}$ and ICl + BPA 200 groups were subcutaneously injected with $\mathrm{ICl} 30 \mathrm{~min}$ before BPA administration. At the same time, rats from the solvent-control-, BPA- and $\mathrm{E}_{2}$-treated groups were injected with $0.5 \%$ ethanol in corn oil. After $30 \mathrm{~min}$, rats in the BPA and $\mathrm{ICl}+\mathrm{BPA} 200$ groups were treated with corn oil-diluted BPA by gavage; rats in the $E_{2}$ group were injected with $E_{2}$ subcutaneously. Meanwhile, rats from the solvent-control-, ICl- and $\mathrm{E}_{2}$-treated groups were administered an equivalent volume of corn oil without BPA or $E_{2}$. All treatments were performed for 60 consecutive days to cross one cycle of spermatogenesis ( 12.9 days/cycle $\times 4.5$ cycles). ${ }^{27}$

Collection of biological samples and heart perfusion. After treatment, rats were anesthetized with $20 \%$ urethane. Blood samples were collected from the right ventricle to measure hormone levels. The left epididymis and testicle were removed and weighed, and the cauda epididymis was used for sperm analysis; the left testicle was used for a meiotic chromosomal spread analysis and alkaline comet assay. Then, perfusion-fixation was performed with saline perfusion through the left cardiac ventricle and followed with $4 \%$ paraformaldehyde (Sigma-Aldrich). The fixed right epididymis and testicle were used for paraffin sections for hematoxylin and eosin (H\&E) or periodic acid schiff-hematoxylin (PAS-H) staining.

Epididymal sperm count, motility, and morphology. As previously described, ${ }^{50}$ cauda epididymides were chopped into $2 \mathrm{ml}$ of Ham's F-12 (GIBCO, Grand Island, NY, USA) and incubated for $5 \mathrm{~min}$ at $37^{\circ} \mathrm{C}$ to allow their contents to spread into the medium. Then, $5 \mu$ l of epididymal sperm suspension was diluted with $195 \mu \mathrm{l}$ of Ham's F-12 medium. The number of epididymal sperm was determined using a hemocytometer under a light microscope (Leica DM6000 B, Wetzlar, Germany) at $200 \times$ magnification. The final sperm concentration was calculated, and the results were expressed as $10^{8} / \mathrm{g}$ epididymal weight. Sperm motility and morphology were examined according to the WHO guidelines. The results were expressed as motile sperm $(A+B)(\%)$ and normal sperm morphology $(\%)$. For each individual, a total of 300 sperm were examined at $\times 400$ magnification.

Assessment of sperm apoptosis (Annexin V/PI assay). Apoptotic sperm was detected using the Annexin V-FITC Apoptosis Detection Kit according to the manufacturer's instructions (Roche Diagnostics Corp., Basel, Switzerland). After washing, the sperm pellet was resuspended in Annexin $\mathrm{V}$ Binding Buffer (0.01M HEPES/NaOH, pH 7.2, $0.15 \mathrm{M} \mathrm{NaCl}$, and $2.5 \mathrm{mM} \mathrm{CaCl}_{2}$ ) at room temperature to a concentration of $1 \times 10^{6} \mathrm{sperm} / \mathrm{ml}$. Aliquots $\left(100 \mu \mathrm{l}\right.$ each, $1 \times 10^{5}$ cells) were transferred into 5 -ml culture tubes, and $5 \mu$ of Annexin V-FITC $+1 \mu \mathrm{l}$ of $\mathrm{PI}(50 \mu \mathrm{g} / \mathrm{ml})$ or nothing was added to each sample. The tubes were slightly mixed and incubated at room temperature for $15 \mathrm{~min}$ in the dark. Additional Binding Buffer $(400 \mu l)$ was added to each tube, and the flow cytometric analysis was performed within $5 \mathrm{~min}$.

Hormone assays. Because the FSH and LH levels in some rats were below the detection limit of the chemiluminescence immunoassay (CIA) kits, they were measured using radioimmunoassay kits with a detection limit of $1.0 \mathrm{mlU} / \mathrm{ml}$ (Beijing North Institute of Biological Technology, Beijing, China). Serum testosterone concentrations were measured by CIA kits with a detection limit of $0.02 \mathrm{ng} / \mathrm{ml}$ (Beckman Coulter, Fullerton, CA, USA).

Histological analysis and staging of seminiferous epithelium. Fixed epididymides and testes were embedded in paraffin and serially sectioned $(5 \mu \mathrm{m})$. Epididymides were stained with $\mathrm{H} \& \mathrm{E}$ for histological analysis. Testes were stained with PAS-H to stage the seminiferous epithelium. The sections were analyzed using a Leica light microscope. PAS-H staining and the staging of the rat seminiferous tubules were performed as previously described. ${ }^{51}$

Meiocyte spreading and immunofluorescence. Meiocyte spreading was conducted by a drying-down technique. ${ }^{20}$ Briefly, decapsulated testes were placed in hypotonic extraction buffer $(30 \mathrm{mM}$ Tris, $50 \mathrm{mM}$ sucrose, $17 \mathrm{mM}$ trisodium citrate dehydrate, $5 \mathrm{mM}$ EDTA, $0.5 \mathrm{mM}$ phenylmethylsulfonyl fluoride, $\mathrm{pH} 8.2$ ) and incubated on ice for $60 \mathrm{~min}$. One-inch tubules were then placed in $20 \mu$ l of sucrose solution ( $100 \mathrm{mM}$ sucrose, adjusted with $\mathrm{NaOH}$ to $\mathrm{pH}$ 8.2) and mixed to a cloudy suspension, which was then spread onto two slides dipped in a 
freshly prepared formaldehyde solution (1\% formaldehyde, $0.15 \%$ Triton X-100 in water adjusted with sodium borate to $\mathrm{pH}$ 9.2). Slides were then dried slowly in humidified chambers for $2-3 \mathrm{~h}$. The immunostaining protocol was adapted from Brower et al.. ${ }^{52}$ Slides were incubated for 15 min in dilution buffer (3\% BSA, $0.5 \%$ Triton X-100 in PBS). After washing, slides were incubated with mouse monoclonal anti- $\gamma \mathrm{H} 2 \mathrm{AX}$ antibodies (1:500; phosphor S139, ab18311, Abcam, Cambridge, MA, USA) at $4{ }^{\circ} \mathrm{C}$ overnight. The next day, slides were incubated with Alexa Fluor 488-conjugated anti-mouse immunoglobulin $\mathrm{G}(\mathrm{IgG})(\mathrm{H}+\mathrm{L})$ antibody (1:100; Invitrogen Corp., Carlsbad, CA, USA) for $1 \mathrm{~h}$ at room temperature. Alternatively, slides were incubated with the primary antibody rabbit polyclonal anti-SYCP3 (1:500; ab15093, Abcam) for $1 \mathrm{~h}$ at room temperature. Following three 3-min washes in PBS, the slides were incubated with an Alexa Fluor 647conjugated anti-rabbit IgG $(\mathrm{H}+\mathrm{L})$ antibody (1:100; Invitrogen). The slides were then washed in PBS, stained with DAPI (Sigma-Aldrich), and analyzed with a Leica confocal laser scanning microscope (TCS SP2, Wetzlar, Germany).

Flow cytometric analysis. Part of the testis was used for the preparation of single cells as described by Bastos et al..$^{53}$ Decapsulated testes were subjected to serial mechanical dissociation and two-step collagenase (GIBCO) enzymatic digestion to obtain a whole-cell suspension that was filtered using $40-\mu \mathrm{m}$ nylon mesh. The filtered cells were fixed in $75 \%$ chilled ethanol and stored at $4{ }^{\circ} \mathrm{C}$ for at least $24 \mathrm{~h}$. Fixed testicular cells were washed twice with PBS and treated with $1 \mathrm{ml}$ of staining solution containing $50 \mu \mathrm{g} / \mathrm{ml} \mathrm{PI}$ (Sigma-Aldrich), $500 \mu \mathrm{g} / \mathrm{ml}$ RNase (Sigma-Aldrich), and $0.1 \%$ Triton X-100 in PBS for 20 min at $37^{\circ} \mathrm{C}$ in the dark. The cells were analyzed using a FACSCalibur system (FACSAria, BD Biosciences, CA, USA), counting 30000 cells in each sample. The testicular cell populations were classified as 1C-, 2C- ,and 4C-DNA content subpopulations according to their DNA content. The percentages of cells in each phase were calculated using the Cell ModFit software program (Becton-Dickinson, Franklin, NJ, USA).

Germ cell purification and alkaline comet assay. Testicular germ cells were purified as described by Meistrich et al. ${ }^{54}$ Briefly, filtered testicular cells were subjected to a germ cell isolation procedure using elutriation centrifugation. Further purification was conducted by centrifugation through a linear Percoll density gradient (Pharmacia, Uppsala, Sweden) to discriminate round spermatids, pachytene spermatocytes, and cytoplasts of elongated spermatids. A purity of approximately $69 \%$ can be obtained for pachytene spermatocyte isolations, with the contaminating cells consisting of other types of germ cells. Purified germ cells were then subjected to an alkaline comet assay according to the manufacturer's instructions (Trevigen, Gaithersburg, MD, USA). Briefly, cells were combined with low melting agarose onto comet slides (Trevigen). After lysis and alkaline unwinding $(\mathrm{pH}>13)$, cells were subjected to electrophoresis for $40 \mathrm{~min}$ at an average of $1 \mathrm{~V} / \mathrm{cm}$. The resulting comets were visualized with diluted SYBR Green I (Invitrogen) and examined at $\times 200$ magnification with a Leica fluorescence microscope (Germany). At least 50 comet images were obtained for each sample and analyzed with a computerbased image analysis system (Comet Assay Software Project; CASPLab, Wroclaw, Poland). Data indicate the mean tail moment.

Western blotting. For western blotting, testicular tissues were homogenized in lysis buffer (Beyotime Company, Jiangsu, China) containing a cocktail of protease inhibitors and phosphatase inhibitors (Roche Diagnostics Corp.). After incubation for $30 \mathrm{~min}$ at $4{ }^{\circ} \mathrm{C}$, samples were then centrifuged at $15000 \times \mathrm{g}$ for $30 \mathrm{~min}$. Supernatants were collected, and the concentration was measured by BCA protein assay kit (Beyotime). Protein extracts from each sample were added to a gel loading buffer (100 mM Tris, pH 6.8, 20\% glycerol, $200 \mathrm{mM}$ DTT, $4 \%$ SDS, $0.03 \%$ bromophenol blue) and boiled for $10 \mathrm{~min}$ at $97^{\circ} \mathrm{C}$. Proteins $(100 \mu \mathrm{g} / \mathrm{sample})$ in loading buffer were subjected to electrophoresis in $10 \%$ SDS-polyacrylamide gel for $1.5 \mathrm{~h}$. The gel was transferred electrophoretically onto a polyvinylidene fluoridemembrane (Immobilon-P; Millipore Corp., Bedford, MA, USA) and blocked in $5 \%$ nonfat powdered milk in PBS for $1 \mathrm{~h}$. The membranes were then incubated with mouse monoclonal antibody against $\gamma \mathrm{H} 2 \mathrm{AX}$ or rabbit polyclonal antibody against p-Chk2 (ab59408, Abcam) or Caspase 3 (9662S, Cell Signaling Technology, Beverly, MA, USA) or $\beta$-actin (Sigma-Aldrich, 1:1000) overnight at $4{ }^{\circ} \mathrm{C}$. After washes in PBS containing $0.1 \%$ Tween-20 for three times for $5 \mathrm{~min}$ each, the membranes were incubated with horseradish peroxidaseconjugated anti-rabbit or anti-mouse IgG (Abcam, 1:2000). After washes, the blots were developed using an enhanced chemiluminescence (ECL) system (Amersham Corp., CardiV, UK).
TUNEL staining. For the detection of apoptosis, paraffin-embedded sections were stained with the TUNEL technique using an in situ apoptosis detection kit (Roche Diagnostics Corp.) according to the manufacturer's introductions. To assess apoptosis in testicular cells, 100 seminiferous tubules were observed in each section at a magnification of $\times 200$. Seminiferous tubules were chosen according to the same criterion. A histogram of the number of TUNEL-positive germ cells in 100 seminiferous tubules was analyzed.

Statistical analysis. All data were expressed as means and S.E.M. SPSS 13.0 (SPSS Inc., Chicago, IL, USA) was used to perform the unpaired Student's $t$-test for comparisons between the two groups. A $P$-value of $<0.05$ was considered statistically significant.

\section{Conflict of Interest}

The authors declare no conflict of interest.

Acknowledgements. This work was supported by the National Basic Research Program of China (National 973 Program; Grant No.: 2011CB503700) and the National Natural Science Foundation of China (Grant No: 31170800).

1. Vandenberg LN, Chahoud I, Heindel JJ, Padmanabhan V, Paumgartten FJR, Schoenfelder G. Urinary, circulating, and tissue biomonitoring studies indicate widespread exposure to bisphenol A. Environ Health Perspect 2010; 118: 1055-1070.

2. Lang IA, Galloway TS, Scarlett A, Henley WE, Depledge M, Wallace RB et al. Association of urinary bisphenol $\mathrm{A}$ concentration with medical disorders and laboratory abnormalities in adults. JAMA 2008; 300: 1303-1310.

3. Trasande L, Attina TM, Blustein J. Association between urinary bisphenol A concentration and obesity prevalence in children and adolescents. JAMA 2012; 308: 1113-1121.

4. Jasarevic E, Sieli PT, Twellman EE, Welsh TH Jr., Schachtman TR, Roberts RM et al. Disruption of adult expression of sexually selected traits by developmental exposure to bisphenol A. Proc Natl Acad Sci USA 2011; 108: 11715-11720.

5. Jenkins S, Wang J, Eltoum I, Desmond R, Lamartiniere CA. Chronic oral exposure to bisphenol $A$ results in a nonmonotonic dose response in mammary carcinogenesis and metastasis in MMTV-erbB2 mice. Environ Health Perspect 2011; 119: 1604-1609.

6. Li DK, Zhou Z, Miao M, He Y, Wang J, Ferber J et al. Urine bisphenol-A (BPA) level in relation to semen quality. Fertil steril 2011; 95: 625-630 e621-624.

7. Souter IDI, Smith K, Ehrlich S, Berry K, Hauser R. Urinary bisphenol A (BPA) concentrations and ovarian reserve in women undergoing infertility treatments. Human Reprod 2011; 26(SUPPL: 1): i6.

8. Cabaton NJ, Wadia PR, Rubin BS, Zalko D, Schaeberle CM, Askenase MH et al. Perinatal exposure to environmentally relevant levels of bisphenol A decreases fertility and fecundity in CD-1 mice. Environ Health Perspect 2011; 119: 547-552.

9. Susiarjo M, Hassold TJ, Freeman E, Hunt PA. Bisphenol A exposure in utero disrupts early oogenesis in the mouse. PLoS Genet 2007; 3: e5

10. Salian S, Doshi T, Vanage G. Neonatal exposure of male rats to bisphenol A impairs fertility and expression of sertoli cell junctional proteins in the testis. Toxicology 2009; 265: 56-67.

11. Meeker JD, Ehrlich S, Toth TL, Wright DL, Calafat AM, Trisini AT et al. Semen quality and sperm DNA damage in relation to urinary bisphenol $A$ among men from an infertility clinic. Reprod Toxicol 2010; 30: 532-539.

12. Ryan $B C$, Hotchkiss AK, Crofton KM, Gray LE Jr. In utero and lactational exposure to bisphenol $A$, in contrast to ethinyl estradiol, does not alter sexually dimorphic behavior, puberty, fertility, and anatomy of female LE rats. Toxicol Sci 2010; 114: 133-148.

13. Howdeshell KL, Furr J, Lambright CR, Wilson VS, Ryan BC, Gray LE Jr. Gestational and lactational exposure to ethinyl estradiol, but not bisphenol A, decreases androgendependent reproductive organ weights and epididymal sperm abundance in the male long evans hooded rat. Toxicol Sci 2008; 102: 371-382

14. Allard P, Colaiacovo MP. Bisphenol A impairs the double-strand break repair machinery in the germline and causes chromosome abnormalities. Proc Natl Acad Sci USA 2010; 107: 20405-20410.

15. Brieno-Enriquez MA, Robles P, Camats-Tarruella N, Garcia-Cruz R, Roig I, Cabero L et al. Human meiotic progression and recombination are affected by Bisphenol $A$ exposure during in vitro human oocyte development. Hum Reprod 2011; 26: 2807-2818.

16. Hunt PA, Koehler KE, Susiarjo M, Hodges CA, llagan A, Voigt RC et al. Bisphenol a exposure causes meiotic aneuploidy in the female mouse. Curr Biol 2003; 13: 546-553.

17. Lenie S, Cortvrindt R, Eichenlaub-Ritter U, Smitz J. Continuous exposure to bisphenol A during in vitro follicular development induces meiotic abnormalities. Mutat Res 2008; 651: 71-81.

18. Sasaki M, Lange J, Keeney S. Genome destabilization by homologous recombination in the germ line. Nat Rev Mol Cell Biol 2010; 11: 182-195.

19. Oliveira H, Loureiro J, Filipe L, Santos C, Ramalho-Santos J, Sousa M et al. Flow cytometry evaluation of lead and cadmium effects on mouse spermatogenesis. Reprod Toxicol 2006; 22: $529-535$. 
20. Peters AH, Plug AW, van Vugt MJ, de Boer P. A drying-down technique for the spreading of mammalian meiocytes from the male and female germline. Chromosome Res 1997; $\mathbf{5}$ : $66-68$.

21. Mahadevaiah SK, Turner JM, Baudat F, Rogakou EP, de Boer P, Blanco-Rodriguez J et al. Recombinational DNA double-strand breaks in mice precede synapsis. Nat Genet 2001; 27: 271-276.

22. Longhese MP, Bonetti D, Guerini I, Manfrini N, Clerici M. DNA double-strand breaks in meiosis: checking their formation, processing and repair. DNA Repair 2009; 8: 1127-1138

23. Lakind JS, Naiman DQ. Bisphenol A (BPA) daily intakes in the United States: estimates from the 2003-2004 NHANES urinary BPA data. J Expo Sci Environ Epidemiol 2008; 18: 608-615.

24. Vandenberg LN, Hauser R, Marcus M, Olea N, Welshons WV. Human exposure to bisphenol A (BPA). Reprod Toxicol 2007; 24: 139-177.

25. Huang YQ, Wong CK, Zheng JS, Bouwman H, Barra R, Wahlstrom B et al. Bisphenol A $(B P A)$ in China: a review of sources, environmental levels, and potential human health impacts. Environ Int 2012; 42: 91-99.

26. Chitra KC, Latchoumycandane C, Mathur PP. Induction of oxidative stress by bisphenol A in the epididymal sperm of rats. Toxicology 2003; 185: 119-127.

27. Quignot N, Arnaud M, Robidel F, Lecomte A, Tournier M, Cren-Olive C et al. Characterization of endocrine-disrupting chemicals based on hormonal balance disruption in male and female adult rats. Reprod Toxicol 2012; 33: 339-352.

28. Herath CB, Jin W, Watanabe G, Arai K, Suzuki AK, Taya K. Adverse effects of environmental toxicants, octylphenol and bisphenol $A$, on male reproductive functions in pubertal rats. Endocrine 2004; 25: 163-172.

29. Ashby J, Tinwell H, Lefevre PA, Joiner R, Haseman J. The effect on sperm production in adult Sprague-Dawley rats exposed by gavage to bisphenol A between postnatal days 91-97. Toxicol Sci 2003; 74: 129-138.

30. Rubio J, Riqueros MI, Gasco M, Yucra S, Miranda S, Gonzales GF. Lepidium meyenii (Maca) reversed the lead acetate induced - damage on reproductive function in male rats. Food Chem Toxicol 2006; 44: 1114-1122.

31. Garagna S, Vasco C, Merico V, Esposito A, Zuccotti M, Redi CA. Effects of a low dose of bentazon on spermatogenesis of mice exposed during foetal, postnatal and adult life. Toxicology 2005; 212: 165-174.

32. Li MW, Mruk DD, Lee WM, Cheng CY. Disruption of the blood-testis barrier integrity by bisphenol $A$ in vitro: is this a suitable model for studying blood-testis barrier dynamics? Int J Biochem Cell Biol 2009; 41: 2302-2314.

33. D'Souza R, Gill-Sharma MK, Pathak S, Kedia N, Kumar R, Balasinor N. Effect of high intratesticular estrogen on the seminiferous epithelium in adult male rats. Mol Cellr Endocrinol 2005; 241: 41-48.

34. Bailis JM, Roeder GS. Pachytene exit controlled by reversal of Mek1-dependent phosphorylation. Cell 2000; 101: 211-221.

35. Xu X, Aprelikova O, Moens P, Deng CX, Furth PA. Impaired meiotic DNA-damage repair and lack of crossing-over during spermatogenesis in BRCA1 full-length isoform deficient mice. Development 2003; 130: 2001-2012.

36. Brieno-Enriquez MA, Reig-Viader R, Cabero L, Toran N, Martinez F, Roig I et al. Gene expression is altered after bisphenol A exposure in human fetal oocytes in vitro. Mol Human Reprod 2012; 18: 171-183.

37. Ulutas OK, Yildiz N, Durmaz E, Ahbab MA, Barlas N, Cok I. An in vivo assessment of the genotoxic potential of bisphenol A and 4-tert-octylphenol in rats. Arch Toxicol 2011; 85: 995-1001.
38. Roos WP, Kaina B. DNA damage-induced cell death by apoptosis. Trends Mol Med 2006 12: $440-450$

39. Bartek J, Lukas J. DNA damage checkpoints: from initiation to recovery or adaptation. Curr Opin Cell Biol 2007; 19: 238-245.

40. Yang J, Xu ZP, Huang Y, Hamrick HE, Duerksen-Hughes PJ, Yu YN. ATM and ATR: sensing DNA damage. W J Gastroenterol 2004; 10: 155-160.

41. Abraham RT. Cell cycle checkpoint signaling through the ATM and ATR kinases. Genes Dev 2001; 15: 2177-2196.

42. Miles $\mathrm{DC}$, van den Bergen JA, Sinclair $\mathrm{AH}$, Western PS. Regulation of the female mouse germ cell cycle during entry into meiosis. Cell Cycle 2010; 9: 408-418.

43. Fang H, Tong W, Perkins R, Soto AM, Prechtl NV, Sheehan DM. Quantitative comparisons of in vitro assays for estrogenic activities. Environ Health Perspect 2000; 108: 723-729.

44. Hugo ER, Brandebourg TD, Woo JG, Loftus J, Alexander JW, Ben-Jonathan N. Bisphenol $A$ at environmentally relevant doses inhibits adiponectin release from human adipose tissue explants and adipocytes. Environ Health Perspect 2008; 116: 1642-1647.

45. Bois C, Delalande C, Nurmio M, Parvinen M, Zanatta L, Toppari J et al. Age- and cell-related gene expression of aromatase and estrogen receptors in the rat testis. $\mathrm{J} \mathrm{Mol}$ Endocrinol 2010; 45: 147-159.

46. Pedram A, Razandi M, Evinger AJ, Lee E, Levin ER. Estrogen inhibits ATR signaling to cell cycle checkpoints and DNA repair. Mol Biol Cell 2009; 20: 3374-3389.

47. Volle DH, Decourteix M, Garo E, McNeilly J, Fenichel P, Auwerx J et al. The orphan nuclear receptor small heterodimer partner mediates male infertility induced by diethylstilbestrol in mice. J Clin Invest 2009; 119: 3752-3764.

48. Nakamura D, Yanagiba $\mathrm{Y}$, Duan Z, Ito $\mathrm{Y}$, Okamura A, Asaeda N et al. Bisphenol A may cause testosterone reduction by adversely affecting both testis and pituitary systems similar to estradiol. Toxicol Lett 2010; 194: 16-25.

49. Jefferson WN, Padilla-Banks E, Phelps JY, Gerrish KE, Williams CJ. Permanent oviduct posteriorization after neonatal exposure to the phytoestrogen genistein. Environ Health Perspect 2011; 119: 1575-1582.

50. Latchoumycandane C, Chitra KC, Mathur PP. The effect of methoxychlor on the epididymal antioxidant system of adult rats. Reprod Toxicol 2002; 16: 161-172.

51. Leblond $\mathrm{CP}$, Clermont $Y$. Definition of the stages of the cycle of the seminiferous epithelium in the rat. Ann NY Acad Sci 1952; 55: 548-573.

52. Brower JV, Lim CH, Jorgensen M, Oh SP, Terada N. Adenine nucleotide translocase 4 deficiency leads to early meiotic arrest of murine male germ cells. Reproduction 2009; 138: 463-470.

53. Bastos H, Lassalle B, Chicheportiche A, Riou L, Testart J, Allemand I et al. Flow cytometric characterization of viable meiotic and postmeiotic cells by Hoechst 33342 in mouse spermatogenesis. Cytometry A 2005; 65: 40-49.

54. Meistrich ML, Longtin J, Brock WA, Grimes SR Jr., Mace ML. Purification of rat spermatogenic cells and preliminary biochemical analysis of these cells. Biol Reprod 1981; 25: 1065-1077.

(c) (i) $\odot$ Cell Death and Disease is an open-access journal BY NG ND published by Nature Publishing Group. This work is licensed under a Creative Commons Attribution-NonCommercialNoDerivs 3.0 Unported License. To view a copy of this license, visit http://creativecommons.org/licenses/by-nc-nd/3.0/ 